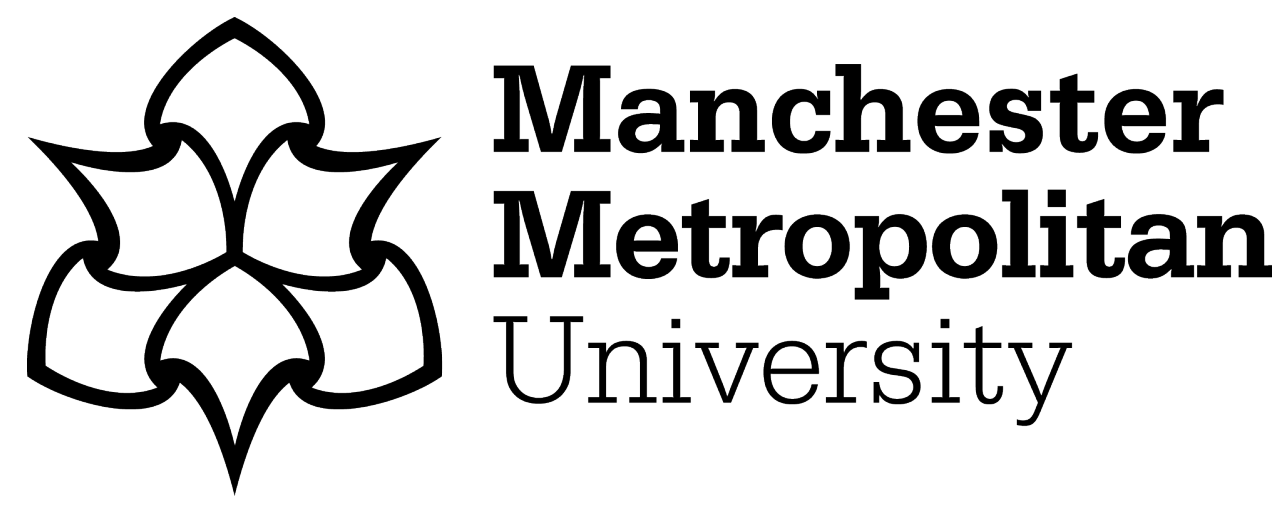

Garratt, Lindsey ORCID logoORCID: https://orcid.org/0000-0002-3775-0695 (2022) Authenticity and Racism: Young boys in three inner city primary schools in Dublin. Journal of Ethnic and Migration Studies, 48 (9). pp. 22582303. ISSN 1469-9451

Downloaded from: https://e-space.mmu.ac.uk/623093/

Version: Accepted Version

Publisher: Taylor \& Francis (Routledge)

DOI: https://doi.org/10.1080/1369183X.2019.1640110

Please cite the published version 
Authenticity and Racism:

Young boys in three inner city primary schools in Dublin.

Lindsey Garratt, Manchester Metropolitan University

Keywords: Authenticity, Racism, The body, Children, Ireland

Word Count: 8,990

Acknowledgements:

Thank you to the reviewers for their helpful comments; also readers of earlier drafts, Alice Bloch, Bridget Byrne, Robbie Gilligan, Alison Jeffers, Aoileann Ní Mhurchú, Andy Smith and Ori Schwarz. Thank you Centre on Dynamics of Ethnicity and the Department of Childhood, Youth and Education Studies, MMU, particularly Kate Pahl and Michael Gallagher. 


\begin{abstract}
This paper examines the role of authenticity as a moral orientation and social evaluation in practices of racism. It will argue that discursive conceptions of authenticity disguises and legitimises racism within micro encounters. Using evidence from a qualitative study of minority children in Ireland, this paper explores how perceptions of 'authenticity' are bound within racist and gendered conceptions of whom can be said to legitimately embody nationally and locally authorised dispositions and identity markers. The specific context of how this played out through the locality of north Dublin and constructed notions of Irishness is examined. The wider implications of a discourse of authenticity are discussed in relation to assumptions of similarity, adaptation and integration. This paper contributes two unique insights, firstly that the passive body (one's appearance) has a central role in perceptions of authenticity and secondly that similarity in one's active body (dispositions and tastes) do not necessarily act as a bridge to bring racialised groups together or facilitate integration.
\end{abstract}

\title{
Introduction.
}

Terminology within immigration studies is proliferated with words such as 'assimilation', 'acculturation' and 'integration'. While these concepts do not retain a consistency of meaning throughout the whole corpus of literature, this vocabulary exists to describe an assumption that those with migrant backgrounds adapt to the norms of majority society (Anthias 2013). Although academic proponents of integration highlight the need for mutual adaptation, a shadow remains unacknowledged, the presumption that certain groups have ownership over characteristics others adapt to. Within the large cohort studies which dominate the field in relation to children, (Rumbaut and Portes 2001; Suarez-Orozco and SuarezOrozco 2002; Berry, Phinney et al. 2006) when minorities demonstrate certain characteristics, beliefs or lifestyle choices they are said to have adapted to a majority norm. The evaluation of this as an adaptation though, creates a power dynamic, as dispositions are characterised as an inherent aspect of one group and the accumulated possession of another. 
In a qualitative study of children in north inner city Dublin, Republic of Ireland [hereafter Ireland], the need to analyse the role of supposed accumulation became crucial for unpicking the racism which existed within inter-ethnic relationships between young boys. In this site, children from all backgrounds appeared to enjoy similar pastimes; most spoke in Dublin accents and all lived in the same neighbourhoods. Yet the fact that minority boys professed an identity as Irish, claimed a localized affiliation to their area, and were interested in the same activities as their classmates was the ground on which their exclusion was ostensibly based. As their majority group peers perceived this behaviour as evidence of minority boys' inauthenticity, rather than belonging. This paper will argue ideas of authenticity are intrinsically related to racialised and gendered understandings of the body, which served to marginalise minority boys. To conclude this paper will suggest these processes are made invisible within an ethos that one has a 'true self' one is aware of, can enact or cynically disguise.

\section{Authenticity and Integration.}

For Weigert (2009) the quest to live authentically has become the master motive of contemporary life and a key component of self-claims to a moral one. This ethic demands that individuals find their true nature and stick to it; act spontaneously and without calculation; and remain true to themselves despite external pressures (Boltanski and Chiapello 2005; Weigert 2009). On questioning the ontology of authenticity, scholarship has predominantly examined it in three ways, as an orientation of action, as dispositional and through a discursive lens. For a full review, see Schwarz (2016). In brief, as an orientation of action, authenticity is both the motivator and product of reflective introspection. In this account, the cultural impetus to be authentic, acts as a framework to shape one's choices and actions. Here authenticity is associated with agency and Boltanski and Chiapello (2005) have gone as far as to contend that the pursuit of an authentic life may provide the seeds from which the very structures of capitalism is challenged, by freeing us from instrumental action. In contrast, a dispositional approach understands authenticity as facilitated by structure. Influenced by Bourdieu (1984), action in this tradition is underpinned by our dispositions, which are acquired in relation to our structural position. Here being authentic is not liberating from social norms, but is facilitated by them. 
For Bernard Lahire (2003) what we understand as authentic comes through a match between one's habitus and field of interaction. Bourdieu defined habitus as, 'a system of lasting, transposable dispositions which, integrating past experiences, functions at every moment as a matrix of perceptions, appreciations, and actions' (2000: 86 -7). Habitus describes the inherited but also adaptable ways individuals have of reading, understanding and interpreting the fields and societies in which they live. The bodily hexis of one habitus is the embodiment of habitus, it is the accent one develops, the manners one employs in social situations, the way one presents oneself and the tastes one develops and exploits, often referred as our dispositions (Bourdieu 1984). From a Bourdieusian perspective, action is rooted in habitus, and therefore may not challenge structures but embed them further. This approach is appealing for analysing authenticity, especially in relation to those who change position, as feelings of inauthenticity within the processes of mobility can be understood as a product of the incongruence of one's habitus and habitat (Reay 2002). As Bourdieu (1984) stressed, late acquisition of habits and dispositions constitutes a 'second language', which is always partial and distinguishable from earlier socialization. He contends that within interaction, the minutiae of one's conduct often betrays one's background and curtails one's chances of capitalizing on acquired dispositions (Schwarz 2016). For Lahire (2003) a mismatch between habitat and habitus can lead to feelings of inauthenticity.

However one may feel authentic but not be perceived or accepted as such by others. For Schwarz (2016) this may be due to defining authenticity as faithfulness to a discursive category where being inauthentic is the effect of occupying a position where no collective subject position exists. This approach has analytic appeal, especially to consider anti-stereotypical groups. For instance both Archer (2012) and Rollock et al (2013) have identified that middle class minorities are prone to being interpreted as inauthentic, due to the racialisation of socio-economic status. Scully's $(2012 ; 2015)$ work on Irish identities for $2^{\text {nd }}$ generation people living in the U.K. also draws on discursive arguments. He contends authenticity is a complex interplay between individual and collective identities, where a personal identity must be reflected in the collective and the collective recognised as authentic in the wider discursive structure of whom is considered Irish. Scully argues this is a considerable problem for Irish people in Britain as individuals are linked with the reference group 
from which 'Irishness' has been explicitly built against (Hickman et al. 2005).

While constructions of Irishness in its relationship to Britain are discussed below, in contemporary times scholars have also examined the covert ways in which nationalism has shaped Ireland's integration strategy. In 2006 the Irish government adopted an integration policy and migration scholars have highlighted the subtle processes of exclusion hidden within this approach (Fanning 2016, Devine 2011). For Devine (2011) intercultural educational policies in Ireland, operate as a form of symbolic power, which reproduces racial power relations while masked as egalitarian interculturalism. Indeed Bryan (2009) and Kitching (2010) have argued Irish education policy reproduces dominant culture's ideology and propagates power inequalities. Bryan (2008) argues while formal integration policies overtly celebrate migrants and cite mutual adaptation, latent within the language of these texts is an assumed 'we' that accepts diversity, which is neither problematised nor recognised as diverse in itself. For Kitching this is 'an unnamed white-Irishness' which is privileged in terms of the 'intelligibility of the nation state' (2010: 215). Thus, even within intercultural policy, there is a covert entrenchment of whom can be said to belong to the nation, or perhaps more accurately whom owns the nation, and can act as managers of national space (Hage 1998). However, what is missing from discussions of integration policy in Ireland and internationally is a focus on the central assumptions that similarity brings people together.

The definition of integration augments between disciplinary fields, but in relation to children, Berry's et al. (2006) description of a process of mutual accommodation where migrant groups adapt to dominant society and dominant society augments to reflect and incorporate migrants, is often used. The actual process of integrating for migrants though is often referred to as acculturation, which describes the stages migrants go through as they adjust to living in a new society (Gordon 1964). A detailed analysis of the complexities of these terms can be found elsewhere (see Mathieu 2018). At its most basic, this language attempts to describe how similar migrants and the majority group are to one another or offer a strategy to create similarity. In some cases, this has been useful for measuring disparities in economic, residential and education opportunities (Clark et al. 2018). However, structural inequality is often overshadowed by narratives of culture (Anthias 2013). Dominant 
notions of cultural integration ascribe certain qualities to groups that must be brought into alignment, or 'integrated' for community cohesion (Fanning 2016). Policy approaches rooted in this approach ostensibly discourage a multiplicity of opinions, values and beliefs in favour of renegotiating common values and cultural expressions (Berry et al 2006). It is on the point of commonality that this paper concentrates, the argument here is that integration discourses are intrinsically flawed due to the core supposition that similarity brings people together. This contention is presented on two grounds, firstly that cultural similarity is not simply there, an objective and unproblematic object; and secondly that objective cultural similarity does not necessarily blur symbolic and social boundaries. The data here will show that objective similarities in dispositions and practices can fail to erase symbolic and social boundaries, and indeed help accentuate and bolster them. This is so as similarity is constructed and its very existence and meaning are shaped by racialised discourses of authenticity.

Moreover, this paper will introduce the body as a key component in how one is read by others as authentic. Within the Bourdieusian tradition, the body is considered important as the carrier of embodied cultural dispositions (Bourdieu 1984). For Lahire (2003) our bodily hexis draws boundaries around identities, signifying our relationship to fields and those within them, marking us as those that belong, from those who do not. The argument of this paper is that the physical body (what I term the passive body) neutralizes this effect, as discourses of authenticity rooted in racialised discourses of nation and locality structure perception, to the extent that one's dispositions (or what I term the active body) can be perceived as mimetic. Here similarities in dispositions and hexis do not automatically bring people together, as cultural integration policies assume, but can instead be used to justify exclusion.

\section{Methodology.}

Fieldwork for this project was undertaken in north inner city Dublin ${ }^{\mathrm{i}}$ [Northside] and conducted in two phases, initially as part of the Trinity Immigration Initiative ${ }^{\mathrm{ii}}$ [TII], Children Youth and Community Relations Project [CYCR] (Curry et al. 2011). The CYCR project collected demographics from all primary schools within the Northside. Using this information seven schools were selected for qualitative research using 
maximum variation sampling (Patton, 2001). Individual and diode interviews with 343 children were collected along with hundreds of hours of observation. This paper focuses on the experiences of the youngest boys aged 7-8 years from three of these schools ${ }^{\mathrm{iii}}$. Two of the schools, School 1 and School 3 are single sex boys' schools and School 2 is co-educational. In each school just under $30 \%$ of the student body is comprised of students with two migrant parents and each class group included here is reflective of this overall demographic. Class group 3 was revisited in 2010 for the author's work alone at which point the respondents were $8-9$ years, all the pupils had been retained from the previous year and two students who had migrated to Ireland in the previous four years had joined the class. A total number of 42 interviews, from 59 participates, 51 boys, 8 girls, 39 children from the majority group and 20 from minority backgrounds and approximately 150 hours of observation notes are drawn on here.

Those born in Ireland to two parents born in Ireland are described as majority group Irish [MGI] and are racialised as white. All of the children referred to as minority group Irish have two parents born outside of Ireland, some moved in early childhood and are the 1.5 generation (Rumbaut and Portes 2001), others were born in Ireland and are $2^{\text {nd }}$ generation. To be able to write up the findings of this study concise descriptors are required, regional descriptors of minority Irish children's family backgrounds are drawn on, for instance where a child's family are from West Africa they are described as West African Irish [WAI], East Asian Irish [EAI] and South Asian Irish [SAI]. This terminology is imprecise, essentializes categories and does not reflect the children's self-identified ethnicity, which tended to be Irish regardless of background, discussed below. Where a collective description is needed, I will refer to children as minority Irish. All names are pseudonyms and where the original name is culturally specific a pseudonym has been chosen to reflect this. Quotes will be labelled with a school number, background descriptor and age; i.e. school 3, West African Irish, aged eight will be labelled [3,WAI,8] in the second year of observation the label is [3(II),WAI,8].

These labels are inadequate, they play into the problematic language which surrounds the relationship between ethnicity and migration, where minorities risk being continually defined through migration (Sajed 2013) and where language homogenises 
heterogeneous experiences, and separates individuals from the wider population. On this, I wish to address two particular points of tension. Firstly, background information is confined to regional level as more specific details risks disclosing the participants. The small numbers and confined geographical area makes it simple for those who know the Northside to guess the schools involved in this study. Disclosing country of origin threatens the anonymity of those involved. Secondly, the decision to draw on family history opens this paper up to the criticism that it plays into that which it seeks to critique. Namely, defining minority groups through a migrant history qualifies their Irish identity, and in the very telling questions their Irishness. We may ask does a child inherit their parents' migrant status? (Sajed 2003). In this paper 'migrants' and 'migration' are only discussed in relation to wider discussions of the literature, pertinent to discuss in the Irish context, which does not share the same history of social and geographical networks for minority groups, as other Atlantic states (Fanning 2007). Moreover, all of the respondents in this study had very recent family histories of migration (within the last ten years) and many of the children were born outside of Ireland. I prefer Irish labels qualified by region and majority and minority status as opposed to racial labels i.e. 'black Irish' etc., as in other publications which explore the situation of Eastern European Irish children, 'white Irish' loses meaning and I wish to remain consistent across work (Garratt 2018). 'Black' also has a particular freight which is associated with the U.S.A. and U.K. and there is some evidence that African populations often have a different experience to those of Caribbean and American backgrounds (Archer \& Yamashita, 2003). Adopting black and white signifiers also leaves the problem of how children from Asian backgrounds are described through a racial category that does not cite region. The need for brevity, clarity and anonymity has made this terminology necessary, but criticism of this language is necessary and warranted.

\section{Northside Dublin - Authentically Irish?}

It is well documented that Ireland underwent a shift from a net emigrant country to $10 \%$ of its population recorded as 'non-Irish nationals' in 2006 and $11.6 \%$ in 2016 (C.S.O 2018). While it is common to discuss the suddenness of immigration to Ireland, implicit within this is an assumption that the beginning of significant levels of immigration marked the start of diversity, constructing it as a modern creation foisted 
upon the nation rather than an integral part of it (Lentin and McVeigh 2004, Carr 2017). Indeed cultural homogeneity is often the default description of Ireland. Where historical discussions of racism have emerged, it is either as victims of racism through colonialism, as emigrants, or as inhabiting an unstable space of whiteness (Garner 2004, Ignatiev 1995). Thus, while white Irishness is not completely analogous to Anglo-American forms, Kitching (2015) reminds us that Irish nationalism's pursuit of 'Atlantic-European citizenship' (2015: 164) as a white population, has imbued the education system with an understanding of Irishness as a white identity. Thus in a so called homogenous state, racial identity has been ever present.

Less work has focused on the inherent tensions that exist within state validated cultural Irishness and the localized effects of this. Within Ireland, whom and what constitutes 'Irishness' has been integral to the nation, predating its establishment and also giving impetus to the push for independence from Britain (Kiberd 1995). In a sovereign state less than 100 years old, the working out of what 'Irishness' was and whom 'the Irish' were, was a considerable exercise in revisionism, which found coherent articulation in a deliberate nationalist project. The Gaelic revival movement, founded in 1877, claimed to re-discover the Gaelic language, sport and music from remote parts of Western Ireland. However, instead of viewing this as geographically and temporally specific, 'Gaelic' culture was propagated as the true heritage of the whole Island, and institutionalised in the first Fianna Fáil government (Hutchinson 1987). Manifestations of Irishness produced through the revival though did not chime with many people's lived experiences in Dublin. The city has always provided alternative representations of 'Irishness', as home to minority groups, many 'AngloIrish', the industrialised poor and as an urban hub in a country which has explicitly drawn rural narratives as the heart of 'real' Ireland (Aalen et al. 1992). As far back as 1488, a strong urban/rural divide was established in the 'Irish' identity, with urbanised Ireland largely located within the pale ${ }^{\mathrm{iv}}$ (Smyth 2006). While being from the pale was advantageous (for some) during colonisation, it did not necessarily bring privilege in terms of State validated cultural 'Irishness' (Garner 2004). In a country where former Taoiseach Éamon DeValera famously described an 'ideal Ireland' as 'a land whose countryside would be bright with cosy homesteads, whose fields and villages would be joyous with the sounds of industry' (DeValera 1943/1980), urban Ireland stood somewhat outside this vision. 
However this does not mean there is a monolithic rural Irishness that working class and urban expressions of Irishness are permanently excluded from (we need only look at the work of Roddy Doyle and the music of the Dubliners, for evidence of how North Dublin has been drawn on in cultural expressions). Yet it is important to recognise the historic root of cultural nationalism in Ireland. Hutchinson (1987) argues it was cultural, rather than political nationalism, which gave rise to the modern Irish state. The need to differentiate Ireland from Britain and specifically England, left Dublin, once described as 'the second city' of the British empire (Christopher 1997), in a strange position. One of the key grounds on which this tension has played out has been in gendered considerations of Irishness. Ní Laoire (2005) argues hegemonic versions of Irish masculinity have been built around gendered divisions of labour, land-ownership and the patriarchal role of the father, historically policed by the Catholic Church and the Gaelic Athletics Association [GAA]. Whelan (1993) believes the GAA has played a central role in maintaining a division of 'Irishness' along geographical lines, as its largely rural fan base ${ }^{\mathrm{v}}$ has impacted on who has traditionally been understood as truly 'Irish'. In north Dublin, soccer [hereafter football] is the most popular sport, but until recently the GAA designated this a 'foreign' game ${ }^{\mathrm{vi}}$. Cronin (1999) maintains the high levels of support for football in Dublin has been used as evidence of the incongruousness of a simultaneous claim of both an urban and 'Irish' identity. In contrast to Ní Laoire's definition, Goodwin (2002) argues masculine expressions in the Northside are constructed in relation to manual labour, industrialization, chronic unemployment and criminality. Those who settle in the Northside then, enter a locality which has not only experienced high levels of socioeconomic stress, but one whose identity and expressions of 'Irishness' and masculinity are complex (Haase and Byrne 2008).

\section{The Northside in the School.}

The reputation of north Dublin loomed large in young boys' interactions. On my first day in one school I was greeted by the children like this:

I met with the boys today and sat with them at lunch [...] boy 1, boy 2 and boy 3 [all MGI,7] came over to me and asked my background [...] they then started launching into a history of their school and listed the infamous criminals who were once students here [...]. I am surprised, I have no doubt this is bravado to impress me, but they know quite specific details such as the demise of [criminal] due to his 
entanglement with the IRA etc. They name pubs in the local area which they say were his 'offices', and boy 2 mentions his family knew [criminal] and 'he had what was coming to him' [murder]. This has the feel of something they have discussed before, a story which has been told over and over, the folklore ${ }^{\text {vii }}$ and welcome of the Northside. [Fieldnotes 1]

Boys in this class group sought me out to explain their area and school and drew on narratives of organised crime and its supposed links with paramilitary activity in Northern Ireland. While I commented this had the feel of something which had been iterated several times, what is of interest here is not if these descriptions reflect the 'truth' of the area, but rather how this narrative of violence and criminality played out amongst peers. Within the context of living in an area constructed as bubbling with danger, boys who were understood as capable of 'handling' themselves in such an environment had a certain level of respect:

Liam: Everybody [all the children in the school] listens to him. Why does everyone listen to him?

Leo: Because like he can go around Riverside and go anywhere, him and Dara they aren't afraid of them.

Liam: like all the drinkin' and all, they just do what they want like, [...] they know how to handle themselves.

[1,MGI,8 about MGI,8]

The apparent fearlessness of Dara within his local area was something many of his peers talked about and admired. While the vast majority of children were critical of the crime and anti-social behaviour in their neighbourhoods, an individual and their families' reputation as tough, had the effect of enhancing a boy's status within their school. Many were happy to brag about their families' involvement with crime:

My uncle got murdered ${ }^{\text {viii }}$ over there.

Your uncle got murdered, what happened?

There was a scuffle and his uncle went with us, and the next thing you know, do you know the way the mad [place in the city][....] his Da defended my Da and then me and his uncles, my uncle defended him. Then another fella just came up and stabbed the two of them in the back [....] he's in the Joy [Mountjoy prison] now.

$[1, \mathrm{MGI}, 8]$

Sam and Kevin were first cousins and the story of the stabbing of their uncle was mentioned in several interviews. When it came to proving one's worth as a tough boy in the school then, boys from the majority group had a considerable advantage as they brought with them a reputation forged in a construction of the local area as perilous, but which they and their families had negotiated. Moreover, most had no qualms about declaring themselves 'real' Northsiders, both through family lineage and the possession of certain dispositions and hobbies:

I'm a real Northsider 
What does that mean?

What....? I from the north side of Dublin

Right?

And me Da and me Granda and me... [pause]

Great Granda?

Yeah all from the Northside

[3(II),MGI,9]

I'm from Dublin, the Northside, I like football and fighting [laughs]

Yeah?

And we take no messing

To be a 'real' Northsider however suggests there are fake Northsiders and this was a recurring theme when minority boys were discussed.

\section{Being Perceived as 'Authentic'.}

Minority boys, particularly those of West African, South and East Asian background $^{\text {ix }}$, had considerable difficulty being accepted as 'Irish' by their peers and this was painful for many, especially those who had been born in Ireland. To make sense of their exclusion they explicitly drew on their bodies:

And what would they be saying?

Warren: Sometimes they say that I am not from Ireland but I am.

Yes, and why do you think they say you are not from Ireland?

Because my body is not white.

[3(I)WAI,8]

Warren's perception that his phenotypical body is drawn on to preclude him from being Irish had a firm basis, his peers drew on skin colour, hair texture and eye shape to claim that being Irish was linked to a certain appearance:

Irish have to look like this [points to himself]

Look like what?

They are dark like, dark, Irish people aren't dark, they trying to be like us but they aren't

Why do you think you can't be dark and Irish?

You just can't, me Da says the Irish are Celts they are whiter they are, and we're stronger betterer with football and reactin' an' all, when you see them comin' in football it's like don't pass to them you can see they'll be crap, we just know how to do it, just do it like hit the ball! They'd be like 'duh', they just stand there! I see them coming and I go 'No just give me the Irish people for my team'

[3(II)MGI,9]

In this quote the phenotypical body is discussed in terms of what skin colour can be considered 'Irish', but the delineation of what being 'Irish' is in terms of the body doesn't stop at its appearance but at its use. The second half of the quote goes into detail about a mythical Celtic root of Irishness and somehow transposes this onto virtues of hyper-masculinity, a tough and sporty masculinity which is precluded from 
minority boys. To an international audience it may seem ludicrous this boy should claim superiority at football for 'Irish' people, given the substantial literature which has suggested minority males are often tied into racializing discourses through supposed sporting prowess (hooks 2004). However the Northside has a particular profile in Ireland as the heart of a tough working class neighbourhood where football is an important pastime. This boy discusses the virtues of football against other sports:

The GAA is good as well...well football [Gaelic football] [...]

But you won't get the money and cars in it [...] I'd be a footballer first, wrestler second $[. .$.$] Rugby third and GAA last$

Ok why football first?

The money [...] And me Da says it's the best, you'll be set for life Ok is.

Everyone here wants to be a footballer, only culchies really want to be a hurler! [GAA sport] Only Culchies?

Dublin people sometimes play GAA [Football] but not hurlin' well I don't think so anyway.

[3,MGI,9]

The globalisation and commercialism of sport can't be discussed here (see Swain, 2000) but from this quote we get a taste of how this boy links football to his locality, in particular the delineation of what Dublin people like from what 'culchies' [people from rural areas] do, brings to the fore the urbanisation of some sports over others. Indeed 'everyone here' and 'Dublin people' suggests more than a personal preference but rather something collective. A collective sense of 'what we do-ness' was also present in the previous quote, where boundaries around who is good at football were drawn to exclude 'dark' boys. This exclusion was not based simply on perceived difference however, but also on similarity, dark boys were understood as 'trying to be like us'. The use of the word trying here is important, as there was an ethos amongst children that one should just achieve without obvious intent, that one's actions must be somehow reflective of whom one genuinely was and not produced through effort. Here majority group boys reflect on themselves:

I'm just myself [1,MGI, 8]

I just do my what I like

I don't know...I'm, I'm I just am $[3, \mathrm{MGI}, 8]$

In contrast minority boys were almost always conceptualised by others as not being themselves: 
Trying to be something he's not

Pretend he's the greatest
[2,MGI,7 about EAI,7]

[3(II)MGI,8 about SAI,9]

The problem of trying, or being conceptualised as trying while others just are, is that one's actions, no matter how similar to others, are judged as something one has actively sought, rather than an expression of that which one is. To try when effortless achievement is the order of the day undermines all you do. This was poignant in examinations of sporting skill.

Two majority boys in School 1 discuss a minority peer's performance in football:

Mac: Did you see, him? Did you see him yesterday?

Cahal: Oh yeah [laughs]

What? Who?

Mac: Samson he tried to copy Cahal

Cahal: Yeah ah [both laugh extended]

Copy him in what way?

Mac: Right he [Cahal], he got the ball right, and just smacked it up field right and like he didn't even mean to like

Cahal: I didn't mean to I was passing it but in went in

Mac: Yeah went in and Samson right he tried [both laughs] he tried to do the same but it went out right

Cahal: Yeah jaysus

Mac: Like he's always copying like, he's trying to be great like he's not, he's not!

[2,MGI,8 about WAI,8]

In this quote, Cathal's unrehearsed, 'natural' skill which is 'just' accomplished is contrasted to Samson's display, viewed as an attempt to be like Cathal. The implication here it that Samson's embodied skills are not his own. They are somehow the property of Cahal. This pattern was repeated for other embodied dispositions such as accent, the use of certain phrases and deportment:

He changing his accent trying to be Dublin

[2,MGI,8 about EAI,8]

They tell me not to say 'gurrier' [local slang for troublemaker]

$[1, S A I, 8]$

A boy has to move his like this [demonstrates]...he was doing that [demonstrates] not the right way

[3(II),MGI,7 about WAI,8]

There is possessiveness here; a denial that certain embodied characteristics can be an authentic expression of self for minority boys. They suggest that what a minority boy may do or say is an attempt to claim an identity not theirs to claim, that their embodied dispositions are not their own. Even games such as football trading cards carried implications of this sort. In School 2 a boy bought a pack of cards to engage in 
a popular card game at lunchtime, news that he was taking part in this game was greeted by two MGI boys like this:

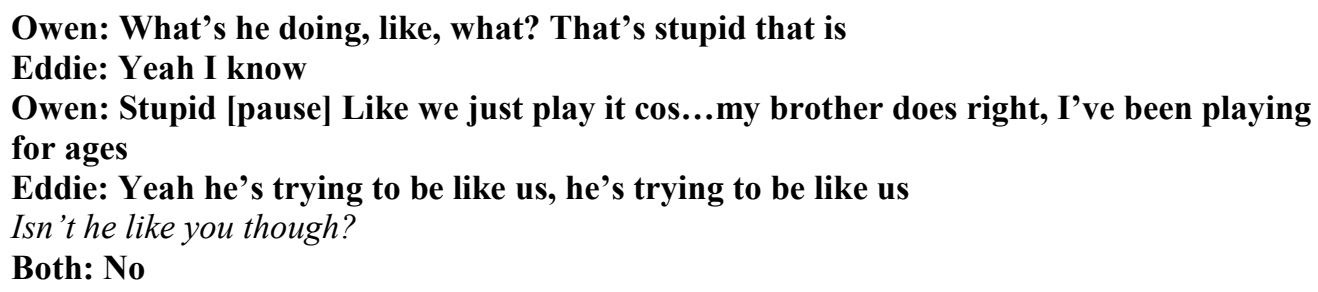

If one's ability to play football authentically, be authentically tough, or even authentically own a pack of cards is in question, as it is 'trying to be like us', what happens to a boy who states they are from the Northside?

Irish [Gaelic] language class, the children have to say their name, where they are from and their age in Irish. The class take turns saying these clips of Irish and largely say the same thing [...]. At little lunch I am talking to Kofi [WAI,8] when Darren [MGI,7] comes up, he asks me 'what is Irish for Africa' I say 'I don't know I'm not very good at Irish' then he says 'An Afraic', he then turns to Kofi and says 'you can use that next time to say where you are from'. Kofi says nothing he looks down.

[Fieldnotes 2,14]

Why did you tell Kofi the Irish for Africa and say he should use that when he says where he is from?

Because that is where he is from

He is from [name of street]

No

Why not?

He's not

$[\ldots]$

Who is from the Northside?

Irish people.

Or that they are Irish:

The foreigners, its all, em you know 'what? what? what?' Rat, rat, rat, cry, cry, cry, and 'where's?' 'what?' they do be like, they'd be saying they's from Ireland Yeah?

Themba and all like doesn't look, he's not, his Ma's not, pretending like.

[3(II),MGI,9 about WAI,8]

\section{Authenticity, Accumulation and the Body.}

On many markers of acculturation, minority boys in this study would score quite highly, they play the same games, speak the same way and many profess a localized and national identity which would please any integrationist. Even those who had recently moved showed a desire to be understood as 'Irish':

\section{Yes I am Irish boy, Ireland my country}


Yet within peer interactions it was on these points of commonality that tension mounted. Majority group boys suggested that minorities were actively taking on an identity that was not theirs. Hage (1998) has argued when we discuss migration and multiculturalism in terms of accumulation the seeds of exclusion are simultaneously sowed. As no matter how much one accumulates, the very fact of this being seen 'as an accumulation leads to its devaluing relative to those who posit themselves to have inherited it or possess it innately without having to accumulate it' (ibid, 64). The promise of belonging which acts as a carrot to adapt, especially in policy narratives, is a fantasy in his analysis, as quantitative accumulation cannot bring equal recognition for minorities, as qualitatively their attributes remain diminished. Pushing Hage's analysis further, the perception that one has accumulated, may not only create exclusion but justify it. As to be conceptualised as taking on something, within an ethos that one should just be, excludes, but also moralises this exclusion, as punishment for not being one's authentic self.

While minority Irish boys were often accused of inauthenticity it was rare for them to view themselves in such terms:

\section{I am me}

We Irish do that

I am true to myself

I am doing my best to live true

To live true?

To live true

What does that mean?

[...] I just am
$[1, W A I, 8]$

[2,SAI,7]

$[3, W A I, 8]$

While the need to say that one is 'true' was qualitatively different for some of these boys, as these declarations tended to be more self-consciously made than those from the majority group (Garratt 2017, 2018). Young boys of $7-9$ years old, living in the Northside, attending the same school and playing childhood games have not necessarily taken on anything, at least not any more so than their peers through processes of local socialisation. Their supposed inauthenticity then, cannot be said to have come from conscious accumulation, but rather from the perception of having accumulated, rooted in the racialisation of what being Irish is, or perhaps more importantly who a Northside boy can be. 
While it would be easy to suggest that being 'black' and 'Irish' is understood as untenable here, because it is a category which is relatively new; this presumes passivity of what it means to be Irish, a function of temporality and demographic size. Yet the history of nation building in Ireland teaches us that many versions of 'Irishness' have been marginalised. Change in whom and what can be considered 'Irish' then is not a matter of course. Scully's $(2012,2015)$ work forces the consideration that notions of authenticity may play a key role in determining who can be considered Irish more broadly. The long history of urban/rural and post-colonial tensions surrounding 'the pale' has arguably made being 'Irish' (in terms of the state sponsored cultural nationalism sense) an identity which is not that securely owned by the long-term residents of the Northside either. Indeed while there is ample evidence here of how local categories are invoked to defend the boundaries of authenticity, understood and represented in nationalist terms; there is also a less precise formulation of simply being 'from here'. This did not always occur in racialised registers, but was rooted in a desire to claim credibility as a Northsider more generally, and defend the attributes of Northsiders as Irish, in contrast to more rural forms. For something to be racializing though, it does not have to be wholly unique, similarity is not the same as equivalency, and processes of racialization can be so dangerous precisely because of how they are insidiously woven within wider dynamics of inequality (Anthias 2012). While authenticity may play a key role in generally defining whom is considered 'Irish' (Scully 2012, 2015), the experiences described here are not one more example of the same, evidence of equal opportunities marginalisation, as the ways in which this played out on and through the body were distinct.

While race does not exist, only processes of racialisation (Murji and Solomos 2005), it is important not to underestimate the material consequences of the phenomenological body as an object within racialised societies (Garratt 2017). Song (2014) has warned against a culture of racial equivalence in scholarship, a flattening out of all racialised activity as racist. Here there were real consequences for children due to their skin colour, hair texture and eye shape, and this was distinct from other types of marginalisation I describe elsewhere (Garratt 2018). Devine (2011) has argued the racialisation of Irishness as intrinsically white makes it tough for visible minorities in Irish schools to be understood as Irish. Having non-white bodies had real implications 
for how authentic minority Irish boys were considered to be. If 'Irish people aren't dark' [3(II),MGI,9], no matter what a boys' personal feelings may be, their bodies were always telling a tale for them in the eyes of their majority peers (Puwar 2004). Indeed, when minority boys asserted their identity as Irish, this often had the opposite effect, rather than affirming their connection to the nation and locality, it tended to provide additional evidence of their inauthenticity:

He's not really Irish

Why?

Look at him [3(II),MGI, about SAI,9]

This tension played out in relation to the supposed contradiction the passive and active body were said to have. When the passive body (ones appearance) is racialised within the discursive structure of whom can be considered to belong; the active body (one's embodiment of locally valued dispositions), will always be talking in contradiction to whom one is considered to be by others. Constructions of authenticity were tied to the body. The phenotypical body marked these children as non-Irish and also as fakes. Their active bodies, or what we may call the bodily hexis of dispositions was judged to be inauthentic against racialized conceptions of the passive body. In this site, minority boys' active bodies were perceived by their peers as articulating an identity and characteristics not theirs to possess, in relation to their passive bodies, particularly their skin colour. Even when minority boys embodied valued forms of being masculine, they could not be considered Irish, because, 'look at him'. Marginalisation here was racist, yet the identification of this as such, was hampered by a moralizing ethic, through which minority boys' actions were reimagined; not as evidence of their similarity and sameness but of their dubious morality, for denying their 'true selves'. However, is a 'true self' even possible?

\section{Authenticity and Duality.}

\section{It's his own fault he is left out} Yeah?

\section{He isn't keeping it real! [laughs]}

[2,MGI,8; talking about SAI,8]

While a discursive approach to authenticity may give us the language to disrupt the simplistic logic of how one may be interpreted as authentic and creates space for supposedly contradictory personal and collective identities to sit together, alone it 
cannot tackle the problem of our belief in the mastery of our own minds. While authenticity may not be as simple as gazing inward for moral direction (Boltanski and Chiapello 2005) but rather linked to collective identities within discursive relations of power (Schwarz 2016), lay accounts, which focus on authenticity as an achievement of internal sensitivity, present a real problem for unpicking these processes of domination:

\section{We're just ourselves, they're not themselves}

What should they be like then?

Themselves, they knows themselves they just pretending they aren't [3(II)MGI,9 talking about WAI,9]

For boys in this study, the belief that one can know ones' true self, have a full account of oneself, which one then chooses to enact or disguise, positioned those with a seemingly incongruent identity, or without what Guignon (2004) describes as a shared background of intelligibility, as morally corrupt. Indeed pretence requires some understanding of what one is diverging from; it implies a choice to be someone or something other than what one is. Self-knowledge in these terms though, only works if we ascribe to a dualist perspective of thought.

I have written on the need to revisit the continued legacy of dualism in studies of racism (Garratt 2017, 2018) and will not repeat these arguments here. In short, dualism requires a belief in the intimate knowledge of our own minds, the main drawback of which is this cannot take into account how our subjective consciousness is structured by its relationship to phenomena, and the conceptualisation of knowledge understood and experienced through our bodies (Garratt 2018). To know oneself in a discreet sense then is impossible, as self-consciousness emerges through our sensuous relationship with the world, which is derived rather than inherent. To be asked to turn back, look at oneself, and know who one is in a complete sense then is absurd; as our authentic self does not reside as a jewel to be discovered by the morally courageous nor ignored by the corrupt. Where it can be said to exist, if at all, is developed through our relationship with the external world, which is somatically experienced. When we look inwards for truth we simultaneously look outwards. From this vantage point we cannot know our 'real' selves outside of our interactions with society and this has serious consequences when that society is racist (Garratt 2017).

Schwarz (2016) best describes the difficulty presented by narratives of authenticity; 
he argues an authenticity ethic encourages introspection as an antidote to constraining social scripts, but prescribes to individuals and groups what they should discover inside based on their ascribed identities. In this site, an ethos that one should be one's true self prevailed, but minority boys were not recognized as such, due to the discursive construction of national and local belonging, which operated on and through their bodies. The complexity of the interweaving of racism and authenticity was flattened out by common sense presumptions that one can know whom one is. Belonging and acceptance were therefore presented to minority boys as something that was theirs for the taking, as long as they didn't 'try to be something you know you're not' [3(II) MGI,9 talking about SAI,9] which was impossible.

\section{Conclusion.}

To the wilfully naïve observer, young boys from many backgrounds playing together should be proof of the success of integration. However, actions that may seem like positive engagement can be interpreted differently within peer groups. In this site, minority boys who showed similar skills, interests and dispositions as the majority were marginalised on the grounds of their similarity. An ethos of authenticity supported a hierarchy, which privileged the majority group to embody dispositions co-opted as local markers of belonging. While the specific nuances described here are context specific, they ask wider questions of policy which focuses on adaptation and similarity, as this case highlights how similarity is constructed. Policies that presume similarity exists as a tangible object, a neutral framework to bring people together, or discuss adaptation as though it were a benign process, need to be reassessed. In this example, cultural similarity was not a bridge for positive inter-ethnic relationships, but rather used as evidence of the inauthenticity of minority boys.

Moreover, while similarity in embodiment of cultural attributes is important, the body mattered here also because of the racialisation of the phenomenological body. It matters because while cultural definitions of integration focus only on dispositional issues of compatibility, skin colour had a powerful bearing on how ones' bodily hexis was perceived. Cultural and dispositional similarity did not exist outside of racialised perceptions of the body. While in a Bourdieusian approach the active body performs and constructs identities, the authenticity discourse and its relationship to the passive 
body, nullified this effect. Here the active body was perceived as mimetic in relation to the passive body, and similarities in dispositions and hexis were either used to justify exclusion, or as I have shown in previous work, completely denied (Garratt 2017). Similarity in dispositions does not necessarily trump racist perceptions of physical bodies. However the insidiousness of these processes are made invisible by a powerful belief in the mastery of our own minds, as they preclude the need to tease out the structures and context of being recognised as belonging, of being the same, of living authentically. 
Aalen, F.H.A., Whelan. K., \& Andrews, J. H. 1992. Dublin, city and county: From prehistory to present : studies in honour of J.H. Andrews. Dublin: Geography Publications.

Anthias, F. 2013. "Moving beyond the Janus face of integration and diversity discourses: towards and intersectional framing" The Sociological Review 61, 323 - 343

-2012. Hierarchies of social location, class and intersectionality: Towards a translocational frame. International Sociology 28(1):121-138.

Archer, L. 2012. "Between authenticity and pretension: parents', pupils' and young professionals' negotiations of minority ethnic middle-class identity." The Sociological Review 60(1): 129 - 148. Archer, L., \& Yamashita, H. 2003. Theorising inner-city masculinities: 'race', class, gender and education. Gender and Education, 15, 115-132.

Garratt, L. 2018. The Body, Authenticity and Racism. London: Routledge.

Garratt, L. 2017. Doubly Estranged: Racism, the Body and Reflection. Ethnic and Racial Studies 40(4): 617-635.

Bannon, M. J., Eustace, J. G., O’Neil, M. 1981. Urbanisation: Problems of Growth and Decay in Dublin. National Economic and Social Council Report. No. 55. Dublin: Stationery Office,

Berry J. W, Phinney J. S., Sam, D.L., Vedder, P. 2006. Immigrant youth in cultural transition: acculturation, identity, and adaptation across national contexts. London, Lawrence Erlbaum Associates.

Boltanski, L., and Chiapello, E. 2005. The Spirit of Capitalism. London, Verso.

Bourdieu, P. 1984. Distinction: A Social Critique of the Judgement of Taste. London: Routledge. 2000. Pascalian Meditations. Cambridge: Polity Press.

Bryan, A. 2008. The Co-Articulation of National Identity and Interculturalism in the Irish Curriculum: Educating for Democratic Citizenship? London Review of Education 6:47-58. 2009. The Intersectionality of Nationalism and Multiculturalism in the Irish Curriculum:

Teaching against Racism. Race and Ethnicity and Education 12:297-317.

Carr, J. 2017. Experiences of Islamophobia: Living with Racism in the Neoliberal Era. London:

Routledge

Christopher, A. J. 1997. “The Second City of the Empire”: colonial Dublin, 1911', Journal of

Historical Geography, 23(2): 151-163

Clark, K., Garratt, L., Li, Y., Lymperopoulou, K,. Shankley, W., 2018. 'Local deprivation and the labour market integration of new migrants to England'. Journal of Ethnic and Migration Studies, https://doi.org/10.1080/1369183X.2018.1481000

C.S.O. 2018. Census of Population 2016 - Profile 7 Migration and Diversity. Dublin, Stationery Office. http://www.cso.ie/en/releasesandpublications/ep/p-cp 7md/p7md/p7anii/ accessed 25/04/2018

Cronin M. 1999. Sport and Nationalism in Ireland: Gaelic Games, Soccer and Irish Identity since 1884. Dublin, Four Courts Press.

Curry, P., Gilligan, R., Garratt, L., and Scholtz, J. 2011. Where to from here? Children and the Future of Integration in Ireland, Dublin: Liffey Press.

DeValera, É. 1943/1980. 'On Language and the Irish nation' in Moynihan, M (ed) Speeches and Statements by Eamon De Valera: 1917-73, Dublin, Gill \& MacMillan

Devine, D. 2011. Immigration and schooling in the Republic of Ireland - making a difference?

Manchester: Manchester University Press.

Fanning, B. 2016. "Integration Convergence and the Irish Case," in Globalization, Migration and Social Transformation: Ireland in Europe and the World. Edited by B. Fanning and R. Munck.

London: Routledge. 2007. Immigration and social change in the Republic of Ireland. Manchester: Manchester

University Press.

Garner, S. 2004. Racism in the Irish Experience. London: Pluto Press

Goodwin, J. 2002. "Irish men and work in North-County Dublin." Journal of Gender Studies 11(2): 151-166.

Gordon, M. 1964. Assimilation in American Life: The Role of Race, Religion and National Origins. New York: Praeger.

Guignon, C. 2004. On Being Authentic. London, Routledge.

Haase, T., \& Byrne, D. 2008. The Changing Face of Dublin's Inner City. Dublin, Pobal.

Hage, G, 1998. White nation: Fantasies of white supremacy in a multicultural society. Annandale, NSW Australia, Merlin Press.

Hickman, M. J., Morgan, S., Walter, B and Bradley, J. 2005. The Limitations of Whiteness and the Boundaries of Englishness - Second-Generation Irish Identifications and Positionings in Multiethnic Britain. Ethnicities 5:160-182. 
Hutchinson, J. 1987. The Dynamics of Cultural Nationalism: The Gaelic Revival and the Creation of the Irish State. Melbourne, Allen and Unwin.

hooks, b. 2004. We real cool black men and masculinity. York: Routledge.

Ignatiev, N. 1995. How the Irish became White. New York: Routledge.

Kitching, K. 2010. An Excavation of the Racialised Politics of Viability Underpinning Education Policy in Ireland. Irish Educational Studies 29 (3): 213-229.

2015. How the Irish became CRT'd? 'Greening' Critical Race Theory, and the pitfalls of a normative Atlantic state view, Race Ethnicity and Education, 18:2, 163-182

Kiberd, D. 1995. Inventing Ireland. London, Johnathan Cape, Random House.

Lahire, B. 2003. 'From the Habitus to an individual heritage of dispositions. Towards a Sociology at the level of the individual'. Poetics 35(2-3): 152 - 167.

Lentin, R., \& McVeigh, R. 2004. After Optimism? Ireland, Racism and Globalisation. Dublin: Metro

Eireann Publications

Mathieu, F. 2018. 'The failure of state multiculturalism in the UK? An analysis of the UK's

multicultural policy for 2000-2015', Ethnicities 18(1): 43-69

Murji, K., and J. Solomos. 2005. "Racialization in Theory and Practice," in Racialization: Studies in

Theory and Practice. Edited by K. Murji and J. Solomos. Oxford: Oxford University Press.

Ni Laoire, C. 2005. "'You're Not a Man at All': Masculinity, Responsibility, and Staying on the Land in Contemporary Ireland." Irish Journal of Sociology 14: 94 - 114.

Haase, T and Pratschke, J. 2017. The 2016 Pobal HP Deprivation Index for Small Areas (SA), Dublin, Pobal.

Patton, M. Q. 2001. Qualitative Research \& Evaluation Methods. London: Sage.

Prunty, J. 1999. Dublin Slums 1800 - 1925: A Study in Urban Geography. Dublin, Irish Academic

Press.

Puwar, N. 2004. Space Invaders: Race, Gender and Bodies Out of Place. Oxford: Berg.

Rollock, N., Vincent, C., Gillborn, D., Ball, S. 2013. "'Middle-Class by profession': Class status and identification amongst the Black middle-class." Ethnicities_13(3): 253 - 275.

Rumbaut, R., \& Portes, A. 2001. Ethnicities: Children of Immigrants in America. Berkeley, Los Angeles, University of California Press.

Sajed, A. 2013. Postcolonial Encounters in International Relations. London: Routledge

Schwarz, O. 2016. The Symbolic Economy of Authenticity as a Form of Symbolic Violence: The Case of Middle-class Minorities. Distinktion: Journal of Social Theory 17(1) 2-19.

Scully, M. 2012. "The tyranny of transnational discourse: 'authenticity' and Irish diasporic identity in Ireland and England." Nations and Nationalism 18(2): 191-209.

2015. The Problem of a Subjective Authenticity and the Articulation of Belonging among the

Irish in England-A Psychosocial Approach, Qualitative Research in Psychology, 12:1, 34-44

Smyth, W. 2006. Map-making, landscapes and memory: a geography of colonial and early modern Ireland c. 1530-1750. Cork, Cork University press.

Song, M. 2014. 'Challenging a culture of racial equivalence' British Journal of Sociology, 65(1), 107129

Suarez-Orozco, C., \& Suarez-Orozco, M. 2002. Children of Immigration. Boston, Harvard University Press Paperback Edition.

Swain, J. 2000. "'The Money's Good, The Fame's Good, The Girls are Good': the role of playground football in the construction of young boys' masculinity in a junior school." British Journal of Sociology of Education 21(1): 95-109.

Weigert, A. 2009. 'Self authenticity as master motive'. in Vannini, P. and Williams, J.P. (eds) Authenticity in culture, self, and society. Surrey, Ashgate.

\footnotetext{
i The 'Northside' is not an administrative district but usually defined as the area north of the river Liffey, between the Grand Canal and Phoenix Park. It is one of the most underprivileged communities in the state in terms of employment, education levels, income and housing tenure (Bannon, Eustace et al. 1981; Prunty 1999; Haase and Pratschke 2016).

ii TII was a cross-disciplinary group studying immigration to Ireland. Within CYCR there were four projects, Learning Together, the North Inner City Schools Survey, a study of secondary schools and a Campbell review.

iii The others were girls only and/or did not include the 7-9 age group.

iv The greater Dublin area.

v Most pronounced in Hurley which is predominantly a rural game, according the GAA Hurley it is the 'most pure representation of an indigenous Gaelic game'.

vi 'Rule 42' prohibited the use of GAA property for 'foreign sports' until 2005. 'Rule 21 banned members of the British armed forces was abolished in 2001.
} 
vii The language in the fieldnotes is sloppy, the narrative of violence expressed by these boys was not the only 'folklore' of the Northside, something embraced by the whole community. Indeed many adults and children distanced themselves from any form of criminality and have a different narratives of what it means to live in a large very diverse part of Dublin City (Author 2018).

viii 'Murdered' is used in its Dublin slang sense to describe a particularly violent incident but no-one was killed.

ix The situation was more nuanced for 'white' groups, many EEI boys were also racialised as 'not white enough' or 'too white' and remained conscious of their bodies as an object which did not fit within discursive space, but their experiences were not as sharp as those racialised as 'black' or 'non-white',

limitations of space do not allow me to discuss this here, for further analysis please see Author (2018). 